\title{
Applications of biomaterials in regenerative medicine
}

\author{
Jane R Choi ${ }^{1,2 *}$ \\ ${ }^{1}$ Centre for Blood Research, Life Sciences Centre, University of British Columbia, 2350 Health Sciences Mall, Vancouver, BC, V6T 1Z3, Canada \\ ${ }^{2}$ Department of Mechanical Engineering, University of British Columbia, 2054-6250 Applied Science Lane, Vancouver, BC V6T 1Z4, Canada
}

Biomaterials play a pivotal role in the field of regenerative medicine especially in the replacement of damaged tissues and organs as well as the treatment of chronic diseases to restore normal body function $[1,2]$. Recent advances in biochemistry, molecular biology, engineering and material sciences have provided wider opportunities for their clinical use. In tissue regeneration, biomaterials usually act as a scaffold to provide the structural support for both cell adhesion and tissue development. They resemble an extracellular matrix (ECM), which is naturally secreted by resident cells to support the surrounding tissues and organs [3]. ECM generally consists of cell adhesion proteins (e.g., laminin and fibronectin), structural proteins (e.g., elastin and collagen), and glycans (e.g., glycosaminoglycans (GAGs) and proteoglycans) [4]. It affords not only spatial organization and physical support, but also a physiological microenvironment that sustains normal cellular functions. Additionally, ECM also contributes to biophysical cues as well as various molecular and signalling events to maintain the cell morphology and phenotype. In response to microenvironmental changes such as mechanical stimuli and all other factors that control the physiological niche (e.g., oxygen and nutrient concentrations), ECM would undergo extensive remodelling [5]. Degradation of the matrix would negatively affect cellular functions including cell growth, survival and differentiation. Therefore, biomaterials have been largely developed to mimic the native structure and composition of ECM and provide structural and functional support to the cells especially for regrowing or regenerating damaged tissues in clinical settings [6].

Natural hydrogels include (i) natural polymers such as chitosan and silk, (ii) ECM proteins such as collagen and elastin, and (iii) ECM originated from various tissues which are subject to decellularization such as dermis, intestinal submucosa and bladder matrix [7]. These materials offer several advantages such as excellent biodegradable and biocompatible, and high flexibility, which possess the capability of changing shape and size to promote the growth of engineered tissue within the surrounding tissues. While most natural hydrogels have attracted much scientific interest due to their inherent outstanding properties, synthetic hydrogels such as polyethylene glycol (PEG) offer more advantages, which include the large-scale production capability and highly tunable physical and mechanical properties, making them significantly useful for 3D cell culturing and tissue engineering [1]. The ability of tuning the properties of hydrogel advances the understanding of interactions between cells and synthetic substrates and recapitulates many of the healthy tissues and disease models. This ability would eventually improve the efficiency of tissue regeneration. Selected commercially available biomaterials are highlighted in Table 1 whereas a number of existing biomaterials for regenerative medicine applications are summarized in Table 2.

To date, multiple challenges are yet to be addressed to translate the existing synthetic biomaterials into practical applications. While being biocompatible, most synthetic hydrogels are synthesized under harsh chemical conditions [8]. The procedures require extra care to ensure that unreacted reagents are ultimately removed to avoid crosscontaminations. Additionally, the capability of some hydrogels to achieve the dynamic and heterogenous nature of the native cellular microenvironment remains elusive [3]. To this end, a variety of manufacturing and processing techniques are being adapted for the synthesis of biomaterials with desirable features and functionality in a safely manner.

Moreover, the use of photochemical reactions to create dynamic microenvironment of hydrogel shows potential in regenerative medicine as these reactions can be conducted in a precise threedimensional space at user-defined time [9]. The spatiotemporal control over chemical reactions can also be performed to achieve optimum functionality of hydrogel [10]. In addition, it is essential to elucidate the molecular pathways between the cells and biomaterials. Studying the mechanism and signalling pathways will review important insights into developing new biomaterials for a more defined cellular response, resulting in a more controlled and efficient tissue regeneration [11].

Even though the structural, mechanical and biochemical properties of native ECM permit the development of new types of tissueengineered constructs, the properties of existing synthetic scaffolds fall short of the criteria for the development of a complex human tissue [12]. This is because of the inability to control all the technical parameters, which limits the study of scaffolds in vivo. In addition, the precise regulation of physiological processes in biomaterials remains a key challenge. It usually includes the process of bioactivation that is normally achieved through the integration of key biomolecules and signals that direct the cells and tissues in vivo [13]. After seeding the cells into hydrogels, the changes in cell behaviour should be monitored periodically in the synthetic microenvironment. The manipulations or signals being introduced should also be tracked while observing the changes in cellular behaviour. In fact, the resulting biomaterials must be both efficacious and cost-effective to be translated into clinical applications. This could lead to an ineluctable dichotomy between the ease and simplicity of scaffold production, and the demand for an appropriate sophistication level by integrating complex yet useful information into scaffold.

${ }^{\star}$ Correspondence to: Jane Ru Choi, Department of Mechanical Engineering, University of British Columbia, 2054-6250 Applied Science Lane, Vancouver, BC V6T 1Z4, Canada, Tel: 604-822-8773; E-mail: janeruchoi@gmail.com, janeru. choi@ubc.ca

Received: March 04, 2019; Accepted: March 18, 2019; Published: March 21, 2019 
Table 1. Selected commercially available biomaterials for regenerative medicine

\begin{tabular}{|c|c|c|c|}
\hline Product & Tissues/ Organs & Description & Company \\
\hline AlloDerm ${ }^{\circledR}$ & Skin & Acellular dermal matrix for soft-tissue augmentation and replacement & LifeCell Corp. \\
\hline Apligraf $^{\circledR}$ & Skin & $\begin{array}{l}\text { Allogeneic fibroblasts on a bovine collagen I matrix with upper } \\
\text { keratinocyte cell layer }\end{array}$ & Organogenesis \\
\hline Dermagraf $^{\mathbb{B}}$ & Skin & Allogeneic fibroblasts on a vicryl mesh scaffold & Shire Regenerative Medicine, Inc \\
\hline GraftJacket $^{\circledR}$ & Skin & $\begin{array}{l}\text { Acellular dermal matrix for soft-tissue augmentation and chronic wound } \\
\text { treatment }\end{array}$ & Wright Medical Technology Inc. \\
\hline TransCyte $^{\circledR}$ & Skin & Allogeneic fibroblasts on a nylon mesh with upper silicone layer & Shire Regenerative Medicine, Inc \\
\hline Oasis $^{\circledR}$ Wound Matrix & Skin & Decellularized porcine small intestinal submucosa & Cook Biotech \\
\hline Integra ${ }^{\circledR}$ Bilayer Wound Matrix & Skin & Type I bovine collagen with chondroitin-6-sulfate and silicone & Integra Life Sciences \\
\hline Epicel $^{\circledR}$ & Skin & Autologous keratinocyte cell sheets & Genzyme \\
\hline Carticel $^{\circledR}$ & Cartilage & Autologous chondrocytes & Genzyme \\
\hline NeoCart ${ }^{\mathbb{B}}$ & Cartilage & Autologous chondrocytes on type I bovine collagen & Histogenics \\
\hline VeriCart $^{\mathrm{TM}}$ & Cartilage & Type I bovine collagen & Histogenics \\
\hline AlloMatrix $^{\circledR}$ & Bone & Demineralized bone matrix combined with calcium sulfate & Weight Medical Technology Inc. \\
\hline Osteoce $\mathrm{l}^{\circledR}$ Plus & Bone & Allogeneic bone with mesenchymal stem cells & NuVasive \\
\hline Pura-Matrix $^{\mathrm{TM}}$ & Bone & Hydrogel composed of a self-assembling peptide & 3DMatrix \\
\hline Osteoscaf $\mathrm{fM}^{\mathrm{TM}}$ & Bone & Poly(lactic-co-glycolic acid) and calcium phosphate scaffold & Tissue Regeneration Therapeutics \\
\hline INFUSE $^{\circledR}$ bone graft & Bone & $\begin{array}{l}\text { Recombinant human bone morphogenetic proteins- } 2 \text { in combination with } \\
\text { bovine type I collagen }\end{array}$ & Medtronics \\
\hline Lifeline $^{\mathrm{TM}}$ & Blood vessels & Autologous fibroblast tubular cell sheet integrated with endothelial cells & Cytograft Tissue Engineering \\
\hline Omniflow $^{\circledR}$ & Blood vessels & Polyester mesh with cross-linked ovine collagen & Binova \\
\hline Anginera $^{\mathrm{TM}}$ & Heart & Allogeneic fibroblasts on vicryl mesh & Theregen \\
\hline $\begin{array}{l}\text { CardioValve }{ }^{\circledR} \text { SynerGraft } \\
\text { Pulmonary Heart Valve }\end{array}$ & Heart & Decellularized allogeneic pulmonary valve & Cryolife \\
\hline
\end{tabular}

Table 2. Selected biomaterials in research and development for regenerative medicine applications

\begin{tabular}{|c|c|c|c|c|}
\hline Tissues/Organs & Cell types & Types of hydrogels & Applications & References \\
\hline Bone & Osteoblasts & $\begin{array}{l}\text { Poly(ethylene glycol) } \\
\text { (PEG), poly(ethylene glycol) poly (lactic } \\
\text { acid) (PEG-PLA) }\end{array}$ & $\begin{array}{l}\text { Drug delivery, cell encapsulation, scaffold } \\
\text { for bone regeneration }\end{array}$ & {$[15,16]$} \\
\hline Heart & $\begin{array}{l}\text { Bone marrow cells, embryonic } \\
\text { stem cells, cardiomyocytes }\end{array}$ & $\begin{array}{l}\text { Fibrin, PEG, alginate, hyaluronic acid } \\
\text { (HA), superabsorbent polymer (SAP) }\end{array}$ & Scaffold for heart tissue engineering & {$[17,18]$} \\
\hline Cartilage & Chondrocytes & Fibrin, PEG, SAP & $\begin{array}{l}\text { Drug delivery, cell encapsulation, scaffold } \\
\text { for cartilage regeneration }\end{array}$ & [19-21] \\
\hline Eye & - & HA & Corneal transplantation & {$[22]$} \\
\hline Skin & Fibroblast & Collagen, fibrin, HA & $\begin{array}{l}\text { Abdominal wall, ear, nose and throat } \\
\text { reconstruction, grafting }\end{array}$ & {$[23,24]$} \\
\hline Blood vessels & Stem cells, endothelial cells & PEG, alginate, $\mathrm{HA}$ & Vascular grafting & {$[25,26]$} \\
\hline
\end{tabular}

More attention should also be paid to the microfabrication technologies that afford an abundance of potential sizes, shapes, porosities, and architectures to create a complex functional engineered tissue or organ for practical use [14]. Integrating the latest biological knowledge and new structural, physical and chemical insights into biomaterials along with a deep understanding of their roles in tissue regeneration are imperative to bridge the gaps in the scientific field. The recent advances in synthetic technology will ultimately yield new generations of multi-functional biomaterials, which could potentially open new approaches in the rapid growing field of regenerative medicine.

\section{References}

1. Mao AS, Mooney DJ (2015) Regenerative medicine: current therapies and future directions. Proc Natl Acad Sci U S A 112: 14452-14459. [Crossref]

2. Sadtler K, Singh A, Wolf MT, Wang X, Pardoll DM, et al. (2016) Design, clinical translation and immunological response of biomaterials in regenerative medicine. Nat Rev Mater 1: 16040.

3. Hinderer S, Layland SL, Schenke-Layland K (2016) ECM and ECM-like materialsbiomaterials for applications in regenerative medicine and cancer therapy. Adv Drug Deliv Rev 97: 260-269. [Crossref]

4. Bonnans C, Chou J, Werb Z (2014) Remodelling the extracellular matrix in development and disease. Nat Rev Mol Cell Biol 15: 786-801. [Crossref]
5. Baker BM, Trappmann B, Wang WY, Sakar MS, Kim IL, et al. (2015) Cell-mediated fibre recruitment drives extracellular matrix mechanosensing in engineered fibrillar microenvironments. Nat Mater 14: 1262. [Crossref]

6. Green JJ, Elisseeff JH (2016) Mimicking biological functionality with polymers for biomedical applications. Nature 540: 386.

7. Brown TE, Anseth KS (2017) Spatiotemporal hydrogel biomaterials for regenerative medicine. Chem Soc Rev 46: 6532-6552. [Crossref]

8. Macdougall LJ, Truong VX, Dove AP (2017) Efficient in situ nucleophilic thiol-yne click chemistry for the synthesis of strong hydrogel materials with tunable properties. ACS Macro Letters 6: 93-97.

9. Ruskowitz ER, DeForest CA (2018) Photoresponsive biomaterials for targeted drug delivery and 4D cell culture. Nat Rev Mater 3: 17087.

10. Skardal A, Atala A (2015) Biomaterials for integration with 3-D bioprinting. Ann Biomed Eng 43: 730-746. [Crossref]

11. Jaganathan SK, Supriyanto E, Murugesan S, Balaji A, Asokan MK (2014) Biomaterials in cardiovascular research: applications and clinical implications. Biomed Res Int: 11.

12. Fallahiarezoudar E, Ahmadipourroudposht M, Idris A, Mohd Yusof N (2015) A review of: application of synthetic scaffold in tissue engineering heart valves. Mater Sci Eng C Mater Biol Appl 48: 556-565. [Crossref]

13. Yim EK, Leong KW (2017) Significance of synthetic nanostructures in dictating cellular response. In Nanomedicine in Cancer. Pan Stanford: 155-184.

14. Yanagawa F, Sugiura S, Kanamori T (2016) Hydrogel microfabrication technology toward three dimensional tissue engineering. Regen Ther 3: 45-57. 
15. Yan Q, Xiao LQ, Tan L, Sun W, Wu T, et al. (2015) Controlled release of simvastatinloaded thermo-sensitive PLGA-PEG-PLGA hydrogel for bone tissue regeneration: in vitro and in vivo characteristics. J Biomed Mater Res A 103: 3580-3589. [Crossref]

16. Vinay R, KusumDevi V (2016) Potential of targeted drug delivery system for the treatment of bone metastasis. Drug Deliv 23: 21-29. [Crossref]

17. Grover G, Christman K (2016) Injectable hydrogels for cardiac tissue regeneration post-myocardial infarction, in Injectable Hydrogels for Regenerative Engineering. World Scientific: $377-414$.

18. Sun X, Nunes SS (2015) Overview of hydrogel-based strategies for application in cardiac tissue regeneration. Biomed Mater 10: 034005. [Crossref]

19. Chen W, Chen S, Morsi Y, El-Hamshary H, El-Newhy M, et al. (2016) Superabsorbent $3 \mathrm{D}$ scaffold based on electrospun nanofibers for cartilage tissue engineering. ACS Appl Mater Interfaces 8: 24415-24425. [Crossref]

20. Wang J, Zhang F, Tsang WP, Wan C, Wu C (2017) Fabrication of injectable high strength hydrogel based on 4-arm star PEG for cartilage tissue engineering. Biomaterials 120: 11-21. [Crossref]
21. Abdul Rahman R, Mohamad Sukri N, Md Nazir N, Ahmad Radzi MA, Zulkifly AH, et al. (2015) The potential of 3-dimensional construct engineered from poly (lactic-coglycolic acid)/fibrin hybrid scaffold seeded with bone marrow mesenchymal stem cells for in vitro cartilage tissue engineering. Tissue Cell 47: 420-430. [Crossref]

22. Xu W, Wang Z, Liu Y, Wang L, Jiang Z, et al. (2018) Carboxymethyl chitosan/gelatin/ hyaluronic acid blended-membranes as epithelia transplanting scaffold for corneal wound healing. Carbohydr Polym 192: 240-250. [Crossref]

23. Bencherif S, Gsib O, Egles C (2017) Fibrin: An underrated biopolymer for skin tissue engineering. J Mol Biol Biotech 2: 1 .

24. Monteiro IP, Shukla A, Marques AP, Reis RL, Hammond PT (2015) Spray-assisted layer-by-layer assembly on hyaluronic acid scaffolds for skin tissue engineering. $J$ Biomed Mater Res A 103: 330-340. [Crossref]

25. Tresoldi C, Pacheco P, Patricia D, Elisa F, Roberta G, et al. (2017) Alginate/Gelatin Hydrogels to Coat Porous Tubular Scaffolds for Vascular Tissue Engineering. Eur Cell Mater: 33 .

26. Rouwkema J, Khademhosseini, A (2016) Vascularization and angiogenesis in tissue engineering: beyond creating static networks. Trends Biotechnol 34: 733-745. [Crossref]

Copyright: ( 92019 Choi JR. This is an open-access article distributed under the terms of the Creative Commons Attribution License, which permits unrestricted use, distribution, and reproduction in any medium, provided the original author and source are credited. 